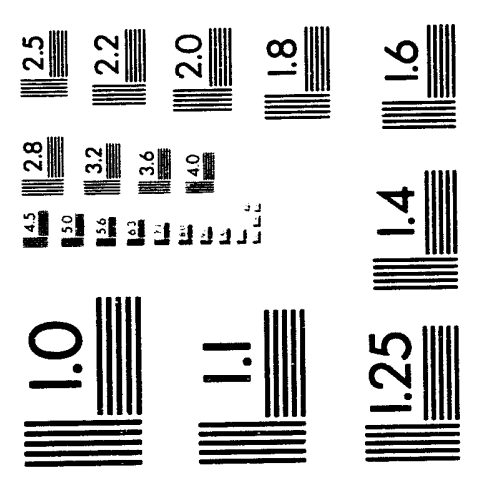



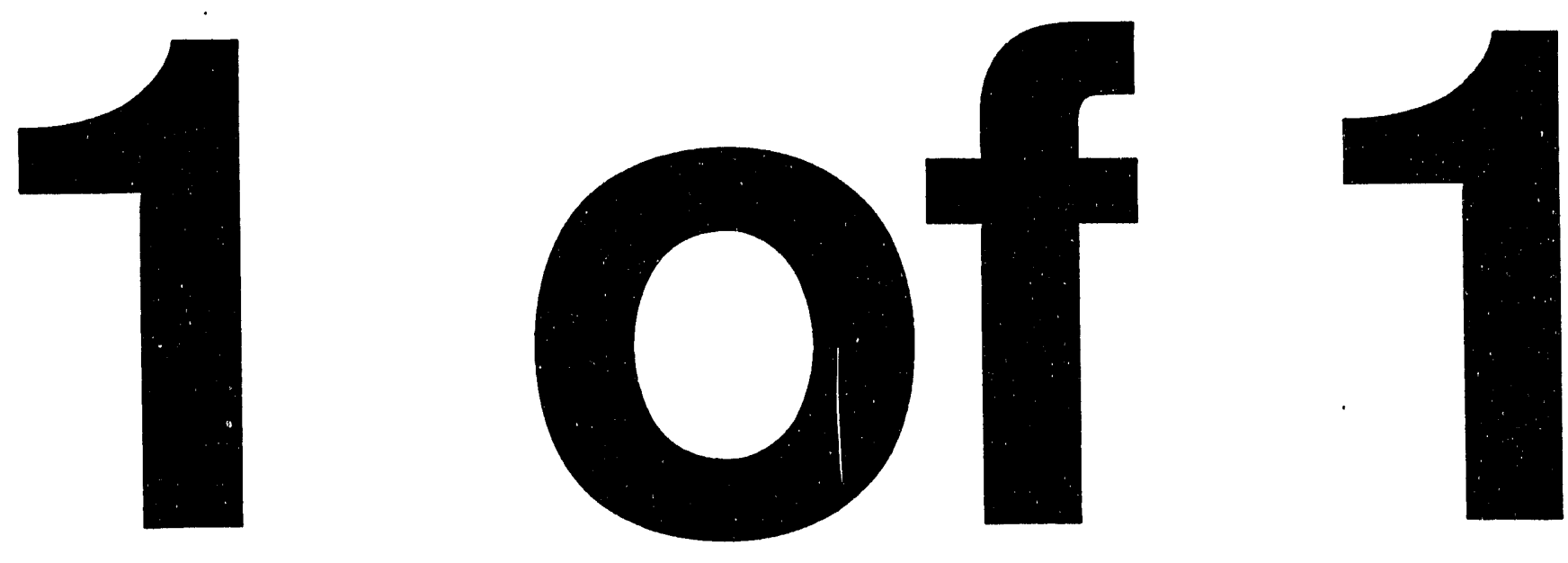


\section{CONF. $931048--13$}

UCRL-JC-107799

PREPRINT

\section{High Density Implosion Experiments at Nova}

M. D. Cable, S. P. Hatchett, M. B. Nelson,

R. A. Lerche, T. J. Murphy, D. B. Ress

This paper was prepared for submittal to the 11th International Workshop on Laser Interaction and Related Plasma Phenomena

Monterey, CA

October 25-29, 1993

February 1994

This is a preprint of a paper intended for publication in a journal or proceedings. Since changes may be made before publication, this preprint is made available with the understanding that it will not be cited or reproduced without the permission of the author. 


\section{DISCI.AIME.R}

This document was prepared as an account of work sponsored by an agency of the L'nited States Government. Neither the linited States (iovernmient nor the Liniversity of California nor any of their employees, makes any warranty, express or implied, or assumes any legal liability or responsibility for the accuracy, completeness, or usefulness of any information, apparatus, product, or process disclosed, or represents that its use would not infringe privately owned rights. Reference herein to any specific commercial products, process, or service by trade name, trademark, manufacturer, or otherwise, does not necessarily constitute or imply its endorsement, recommendation, or favoring by the United States Government or the I'niversity of California. The views and opinions of authors expressed herein do not necessarily state or reflect those of the I'nited States Government thereof, and shall not be used for advertising or product endorsement purposes. 


\title{
High density implosion experiments at Nova*
}

\author{
M. D. Cable, S. P. Hatchett, M. B. Nelson, R. A. Lerche, T. J. Murphy, D. B. Ress
}

A series of - speriments to produce implosions with fuel densities comparable to an ignition scale implosion hot spot (approximately $20 \mathrm{~g} / \mathrm{cm}^{3}$ ) have been done at the Nova Laser Fusion Facility. These implosions utilize indirectly driven, deuterium filled capsules for which the primary measurement of fuel density is the secondary neutron technique. Calculations indicated that by decreasing initial capsule fill pressure, these densities could be achieved across a wide range of convergences up to about 25 . Initial experiments showed a decrease in observed final fuel densities at the highest convergences due to a lack of adequate laser control. Additional work was done to improve laser pointing, power balance, and beam synchronization (Precision Nova) which resulted in improved implosion performance.

The targets were deuterium filiad glass microballoons with $180 \mu \mathrm{m}$ i.d. and $5 \mu \mathrm{m}$ wall thickness. They were coated with $\delta 7 \mu \mathrm{m}$ of $\mathrm{CH}$ ablator. Capsule size was chosen to be smaller than typical Nova capsules (about half) to allow the use of the secondary neutron technique to measure fuel ar aal density; larger capsules would have resulted in an areal density too large for this technique. The smaller capsule size also allowed use of a shorter drive pulse, minimizing sifects of time-dependent asymmetries. Densities and convergences were inferred from the observed fuel areal densities by assuming a "hotspot" model (fuel is sphere with uniform temperature and density, all burn originates at point at center) for the final fuel configuration.

The targets were indirectly driven in a cylindrical hohlraum $2500 \mu \mathrm{m}$ in length, 1600 $\mu \mathrm{m}$ in diameter with laser entrance holes in the ends that were $75 \%$ of the diameter of the hohlraum. The laser drive was a shaped pulse (see Fig. 1) chosen to compress the pusher along a P-V trajectory that was fairly stable hydrodynamically yet reasonably close to an ideal isentropic compression. Total energy of the 10 Nova beams was $21 \mathrm{~kJ}$ at $0.351 \mu \mathrm{m}$. Fig. 1 also shows the corresponding hohlraum temperature as a function of time.

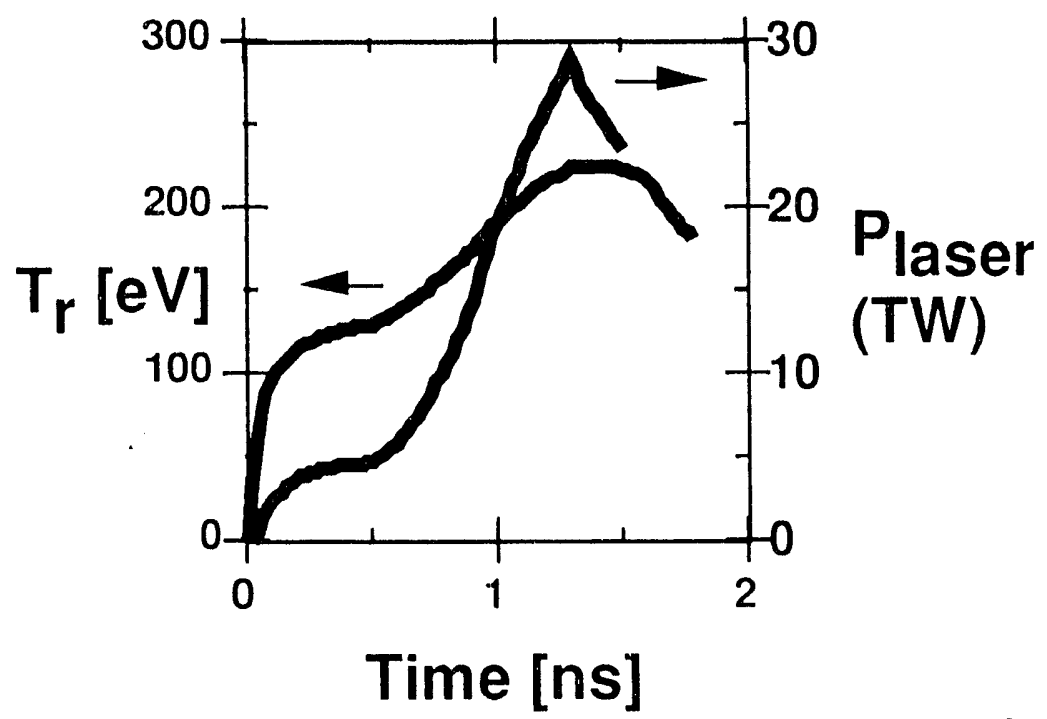

Figure 1. Drive temperature and laser power as a function of time. 
It can be seen in Fig. 2 that calculations show that as capsule fill pressure is varied from 25-200 atm, high fuel densities can be achieved across a wide range of convergence. Initial experiments (labeled "before Precision Nova") did not achieve high densities at high convergences. This was determined to be due to a lack drive symmetry due to inadequacies in laser control. An effort to improve laser control (called "Precision Nova") was undertaken. As a result of these efforts, laser power balance was improved to $8 \%$ RMS in the "foot" of the laser pulse from a previous value of $20 \%$; peak power balance improved to $4 \%$ from $10 \%$. Beam pointing was improved to $30 \mu \mathrm{m}$ RMS from $100 \mu \mathrm{m}$ and relative timing of the 10 Nova beams was improved to $7 \mathrm{ps}$ from a former value of $20 \mathrm{ps}$.

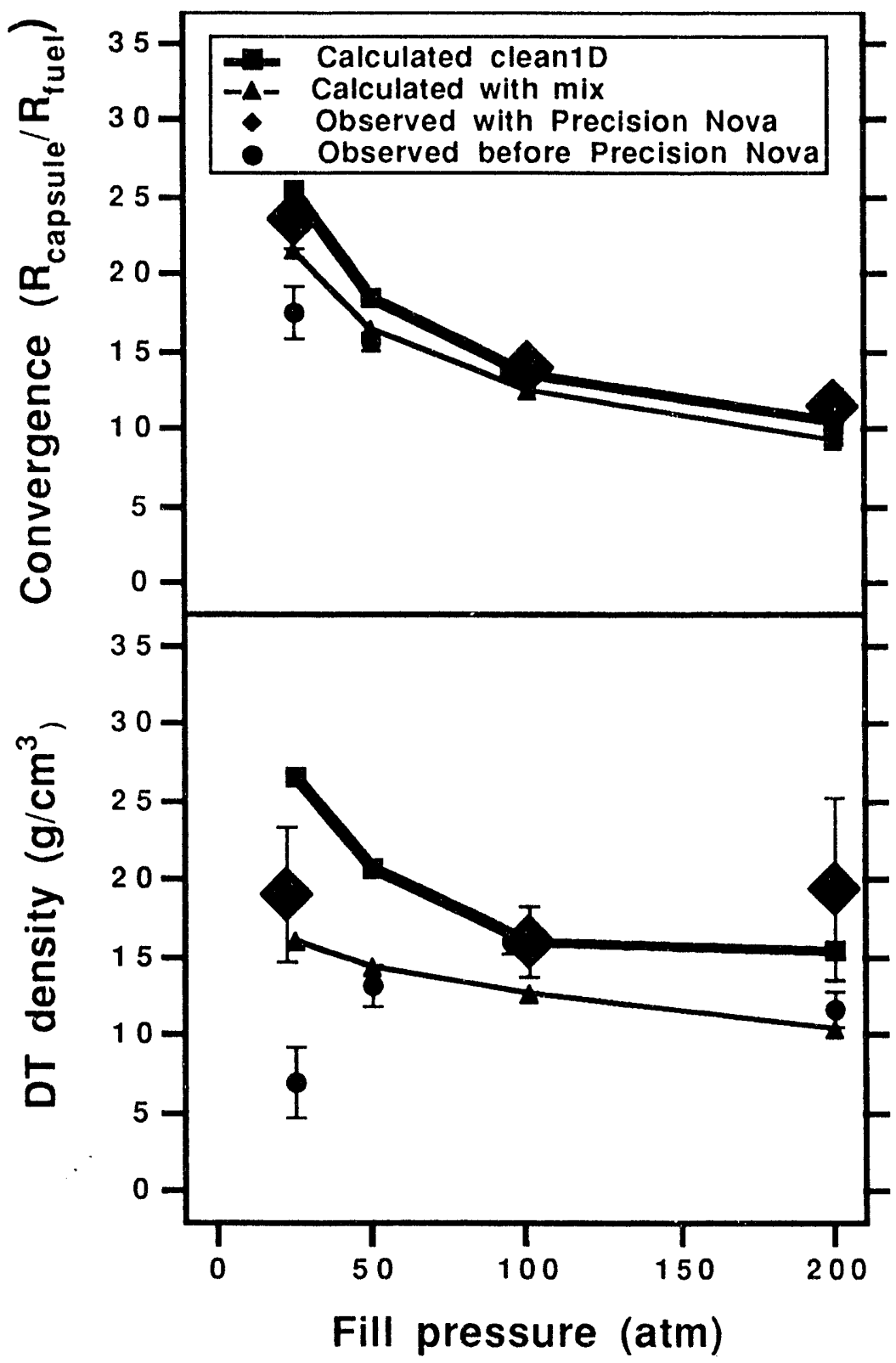

Figure 2. Convergence and density as functions of capsule fill pressure. Density shown is equivalent to that if capsule had been filled with deuterium-tritium as opposed to the pure deuterium used for diagnostic purposes. 
All of these improvements resulted in the drive conditions necessary for the high convergence implosions. It can be seen in Fig. 2 that the points labeled "Observed with Precision Nova" showed increased densities and convergences up to a level consistent with that expected from calculation.

In conclusion, a series of high density implosions has been done that achieved fuel densities and convergences comparable to an ignition scale hot spot. High levels of laser precision were required to accomplish this. *This work was performed under the auspices of the U.S. Department of Energy by Lawrence Livermore National Laboratory under contract No. W-7405-ENG-48. 

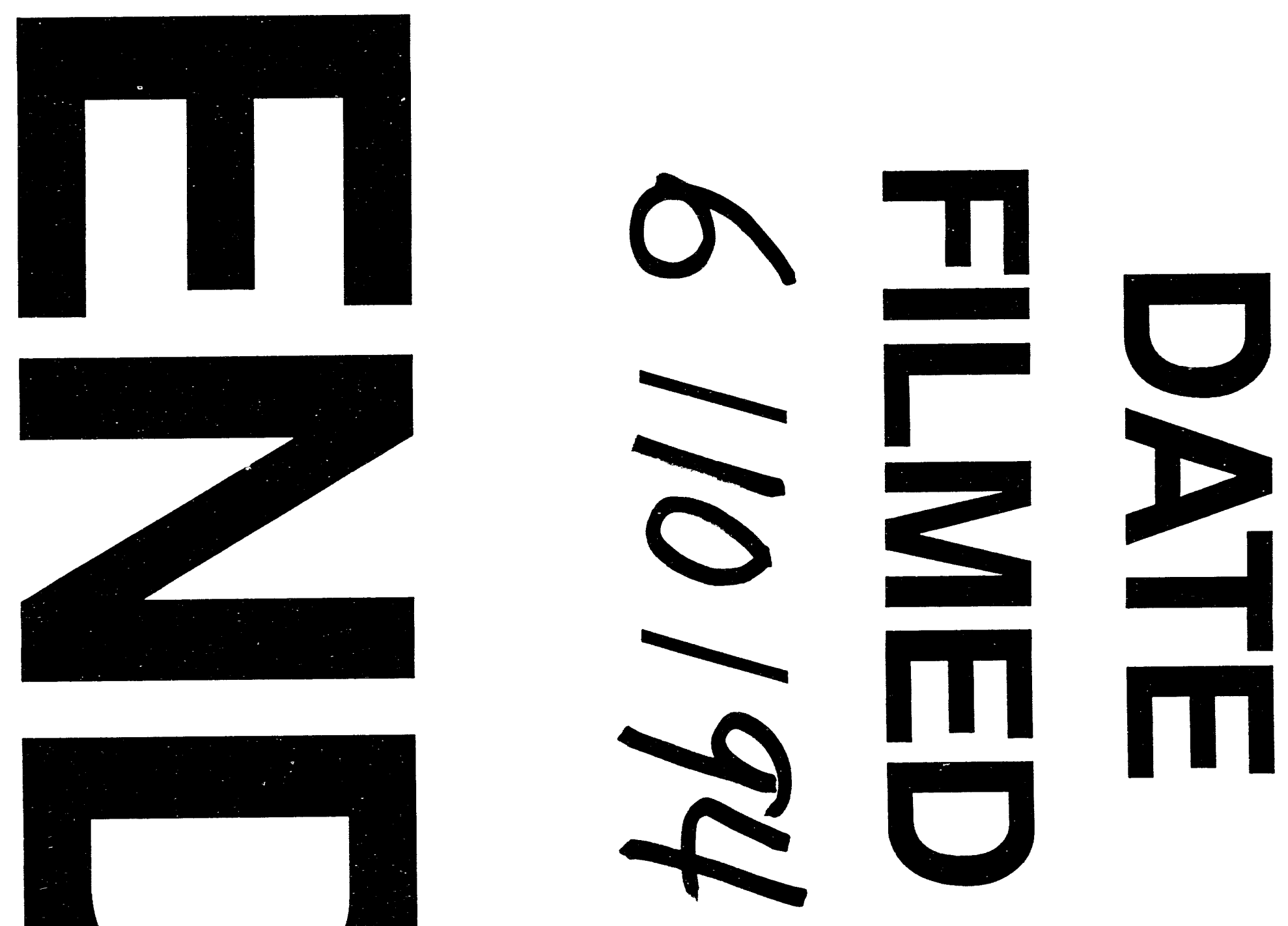
